\title{
Apuntes del feminicidio y violencia de género
}

\section{Notes on feminicide and gender violence}

\author{
Sergio Raúl Isidro Arias ${ }^{1}$, Francisca Silva Hernández²
}

\begin{abstract}
${ }^{1}$ Licenciatura en Derecho por la Universidad Juárez Autónoma de Tabasco. Email: sergioraularias@outlook.com ORCID: http://orcid.org/0000-0002-1715-1046

2Doctora en Métodos de Solución de Conflictos y Derechos Humanos. Profesora Investigadora de la Universidad Juárez Autónoma de Tabasco. Email: fany987@hotmail.com ORCID: http://orcid.org/0000-0003-3533-00023
\end{abstract}

${ }^{3}$ Doctor en Gobierno y Administración Pública. Profesor Investigador de la Universidad Juárez Autónoma de Tabasco. Email: germanmtzprats@hotmail.com ORCID: https://orcid.org/00000001-6371-448X

DoI https://doi.org/10.46589/rdiasf.vi35.371

Recibido 26 de febrero 2021.

Aceptado 2 de junio 2021

Publicado 30 de junio de 2021

\section{Resumen}

Hoy día en una sociedad compleja de respeto y garantía de derechos humanos, en el tema de género se debe contemplar acciones y mecanismos estratégicos en la problemática de feminicidio, dicho delito es recurrente, pone en riesgo y en estado de vulnerabilidad a la población femenina. Este artículo describe aspectos generales del concepto, características y tipos del mismo, a partir de la doctrina y la normativa; enuncia aquellos instrumentos internacionales de los que el estado mexicano es parte y ante dicha situación se deben prever. Es un documento con enfoque cualitativo de alcance descriptivo e interpretativo.

Palabras clave: feminicidio, violencia, género, México.

\begin{abstract}
Nowadays, in a complex society that respects and guarantees human rights, on the issue of gender, strategic actions and mechanisms must be considered in the problem of femicide, this crime is recurrent, putting the female population at risk and in a state of vulnerability. This article describes general aspects of the concept, characteristics and types thereof, based on the doctrine and regulations; it enunciates those international instruments to which the Mexican state is a party
\end{abstract}


and in such a situation they must be foreseen. It is a document with a qualitative approach with a descriptive and interpretive scope.

Keywords: femicide, violence, gender, Mexico.

\section{Introducción}

De acuerdo al Secretariado Ejecutivo de Sistema Nacional de Seguridad Pública (2020) la tendencia nacional del feminicidio va en aumento, ya que en el año 2015 el número de víctimas era de 411 y en el 2019 ascendió a 942 víctimas.

La Comisión Nacional de Derechos Humanos-CNDH (2020) afirma que, de acuerdo a las cifras del Sistema Nacional de Seguridad Pública, dadas a conocer en el mes de mayo de 2019 los asesinatos de mujeres fueron de 10.5 al día, y que en el primer cuatrimestre del año 2020 ascendió a un 10.8, casi 11 mujeres por día.

El artículo denominado "Apuntes del feminicidio y violencia de género" plantea aspectos básicos del tema señalado, describiendo el feminicidio desde su concepción, la existencia de tipos de feminicidio y el panorama en un contexto descriptivo; destacando los derechos humanos violados ante la vida y dignidad de la mujer.

A través de la historia, las mujeres han tenido una evolución de crecimiento y desarrollo en el escenario profesional y laboral, ante diversas circunstancias que la han expuesto en estado de marginación y discriminación; sin embargo, a través de los fenómenos sociales con impacto y atención en el contexto jurídico normativo en el estado mexicano, se ha legislado al respecto para establecer un estado de igualdad y equidad en mujeres y hombres con garantía a los derechos humanos como personas.

Derivado de lo anterior, este documento se basa en un proceso de metodología con enfoque cualitativo (Hernández et al, 2014) de alcance descriptivo e interpretativo de la doctrina, la norma internacional e interna, así como de informes de fuentes oficiales e institucionales.

\section{Concepto de Feminicidio}

Pineda (2019) considera que el femicidio o feminicidio "se entiende como la muerte violenta de mujeres por razones de género, ya sea que tenga lugar dentro de la familia, unidad doméstica o en cualquier otra relación interpersonal, en la 
comunidad, por parte de cualquier persona, o que sea perpetrada o tolerada por el Estado y sus agentes, por acción u omisión; violencia resultante de la posición de subordinación, marginalidad y riesgo en el cual se encuentran las mujeres en la sociedad."

Incháustegui Romero (2014) "conceptualiza el sentido político el (femicidio o feminicidio) queda plenamente establecido, permitiendo no solo distinguir el asesinato de mujeres de otros homicidios, sino además ubicarlo como consecuencia de un orden de dominación patriarcal."

Jiménez (2011) describe que se ha construido el término femicidio como un término jurídico, con connotaciones políticas para identificar y denunciar los asesinatos de las mujeres como resultado extremo de la violencia, asesinatos de mujeres por el hecho de serlo, que se producen tanto en el ámbito privado como en el público, ya que no solo se ejecutan en el terreno de victimarios conocidos, sino también desconocidos; es la violencia basada en la inequidad de sexos, entendida como aquella ejercida por los hombres hacia las mujeres en su deseo de adquirir poder, dominación o control.

Jiménez (2011) citando las palabras de Marcela Lagarde expresa el feminicidio como "el conjunto de delitos de lesa humanidad que contiene los crímenes, los secuestros y las desapariciones de niñas y mujeres en un cuadro de colapso institucional"

Albarrán (2015) manifiesta "el asesinato de las mujeres, por el hecho de ser mujeres, cometido por hombres."

En todas las anteriores concepciones del concepto de feminicidio va implícito acto de violencia, vulnerabilidad y riesgo, privación de la vida a una mujer.

En la Gaceta del Semanario Judicial de la Federación (2018) el Tribunal Colegiado de Circuito considera que para estar frente al delito de feminicidio se tiene que cumplir con los elementos necesarios que marca la tesis aislada "la existencia de datos de violencia previa y concomitante al asesinato de una mujer, son elementos que necesariamente deben conducir a la calificación de los hechos en el delito de feminicidio, pues actualizarlos en la hipótesis relativa al homicidio, conllevaría invisibilizar tanto el contexto de violencia de la víctima, como las acciones afirmativas realizadas en la investigación y juzgamiento de la violencia contra mujeres."

El delito de feminicidio se encuentra tipificado en el Código Penal Federal en el artículo 325 que señala lo siguiente: "comete el delito de feminicidio quien prive de la vida a una mujer por razones de género. Se considera que existen razones de género cuando concurra alguna de las siguientes circunstancias: la 
persona presente signos de violencia sexual y se le hayan infligido lesiones 0 mutilaciones degradantes, existan antecedentes de cualquier tipo de violencia en el ámbito familiar, laboral o escolar; haya existido entre el activo y la víctima una relación sentimental, afectiva o de confianza; que existan datos donde hubo amenazas relacionadas con el hecho delictuoso, acoso o lesiones del sujeto activo en contra de la víctima y que esta haya sido incomunicada"; el delito de feminicidio tiene que encuadrar en la hipótesis que establece el precepto legal.

Las autoras Deus Alicia y González Diana (2018) han descrito tipos y modalidades de muertes violentas de mujeres por violencia de género:

- Intimo: la persona tenía relaciones con su marido, exmarido, novio o concubino

- No íntimo: Muere a manos de un desconocido

- Por conexión: la víctima muere en la línea de fuego donde un hombre asesino o intenta matar a otra mujer

- Infantil: Menor de 14 años por un ser masculino en una relación de responsabilidad, confianza o poder.

- Familiar: Parentesco entre el asesino y su víctima

- Sexual sistémico: Mujeres víctimas de delitos sexuales.

- Sexual sistémico organizado: Personas que actúan como red organizada en delitos sexuales por un período de tiempo.

- Sexual sistémico no organizado: Matarlas por secuestro, violación y tortura sin ninguna planificación en red

- Por prostitución u ocupaciones estigmatizadas: Mujeres que ejercen la prostitución u otra ocupación similares y lo cometen uno o varios sujetos por odio o misoginia.

- Por trata: La muerte o el asesinato en una situación de sometimiento y privación de la libertad por coacción o extracción de sus órganos.

- Por tráfico: El asesinato de la mujer se produce en una situación de tráfico ilegal de migrantes con el fin de obtener beneficios económicos.

- Transfóbico: Por ser una mujer transexual y el o los victimarios la matan por su condición o identidad transexual, por odio o rechazo de la misma.

- Lesbofóbico: La víctima del asesinato es una mujer lesbiana y la asesinan por su orientación sexual

- Racista: Por su origen étnico o sus rasgos fenotípicos, por odio o rechazo hacia los mismos.

- Por mutilación genital femenina: Cuando se practica a una mujer o niña y acaba con la vida de ella. 
En ese sentido, hay que considerar el aspecto normativo internacional que coadyuva al sistema de justicia en México en el que a través del acceso a la justicia y previendo los instrumentos normativo internacionales e internos permiten conocer y ser un mecanismo de garantía de los derechos de las mujeres.

En el marco de atención de riesgo y vulnerabilidad existe un marco jurídico internacional en el que se cuenta con instrumentos universales y regionales relacionados con la erradicación de la violencia en contra de la mujer, los cuales son: Declaración Universal de Derechos Humanos (1948); Convención Americana sobre Derechos Humanos (1969); Convención Interamericana para Prevenir, Sancionar y Erradicar la Violencia contra la Mujer "Convención de Belém Do Pará" (1994); Convención sobre la Eliminación de Todas las Formas de Discriminación contra la Mujer (CEDAW por sus siglas en inglés, 1979); Pacto Internacional de Derechos Civiles y Políticos; Declaración sobre la eliminación de la violencia contra la mujer. Resolución aprobada por la Asamblea General de la Organización de las Naciones Unidas, A/RES/48/104 23 de febrero de 1994. Todos estos tienen en común velar por la integridad física, psicológica, social y económica de las mujeres para una vida digna.

Todas las leyes y marcos jurídicos para la protección de las mujeres, en teoría están muy bien, sin embargo, Pineda (2019) distingue que ante esta situación predomina la inoperancia de los Estados Latinoamericanos, no existen políticas públicas de prevención, los gobiernos se han conformado con la aprobación de penas ejemplificadoras en la normativa jurídica (las cuales en pocos casos son aplicadas porque predomina la impunidad); y la situación de desprotección de las mujeres se profundiza cuando los crímenes contra ellas cometidos son justificados y naturalizados por la población en general, los medios de comunicación y por el sistema penal.

\section{Contextualizando el feminicidio}

En datos de la Oficina de las Naciones Unidas contra la Droga y el Delito, describe el número de mujeres asesinadas en el año 2018 puntualizando que el índice de mujeres asesinadas es originado por su pareja o un familiar. 
Tabla 1. Número de mujeres asesinadas por continente

\begin{tabular}{|c|c|c|c|c|}
\hline África & América & Oceanía & Asia & Europa \\
\hline 3.1 & 1.6 & 1.3 & 0.9 & 0.7 \\
\hline
\end{tabular}

Fuente: Elaboración propia.

Destaca que, de los 5 continentes, los que representan mayor índice son África y América. En la gráfica1 se muestran el número absoluto y tasa de mujeres asesinadas en países de América Latina y el Caribe, la tasa más alta de feminicidio se registra en Centroamérica en República Dominicana, en la subregión del Caribe Guayana y Santa Lucia.

Gráfica 1. Tasa de mujeres asesinadas.

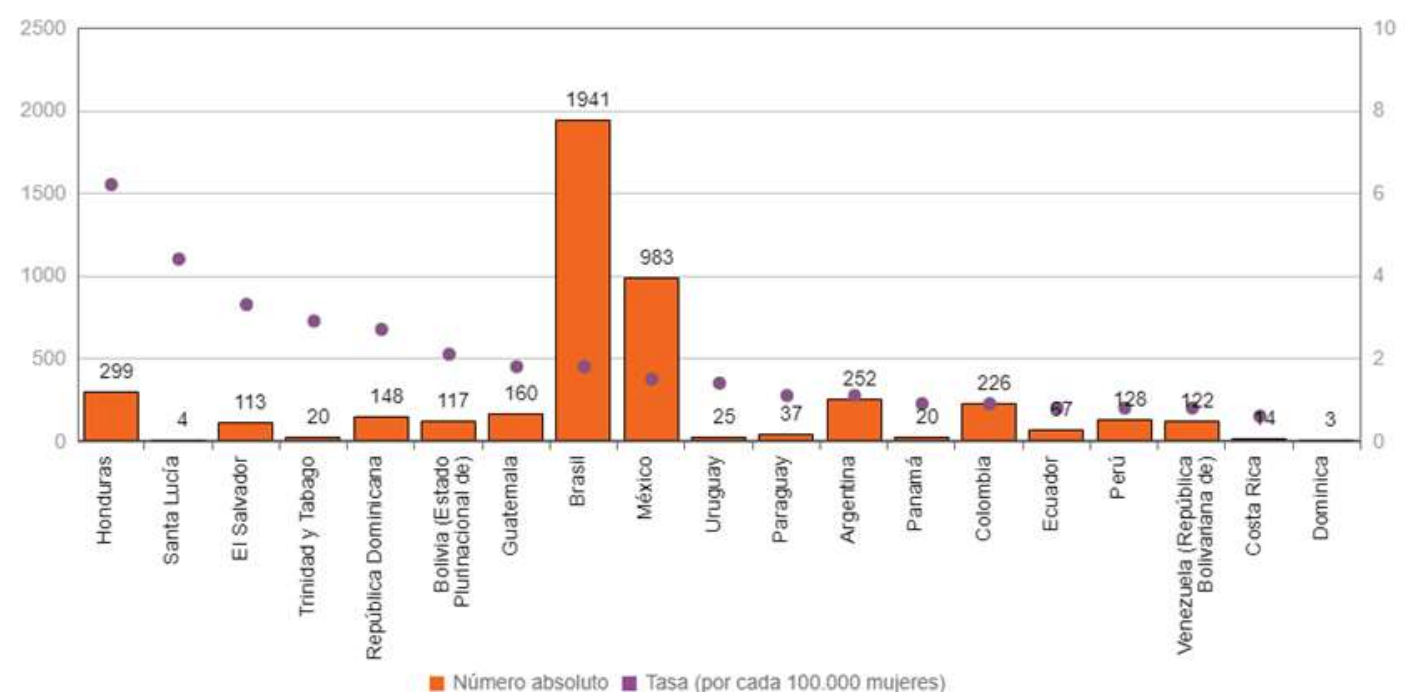

Brasil se encuentra en el primer lugar con 1941 mujeres asesinadas, y el segundo lo ocupa México en razón de género.

La CEPAL (2019) presenta en la gráfica 2, los homicidios en razón de género expresándolos en tasas. 
Gráfica 2. Feminicidio en América Latina y el Caribe.

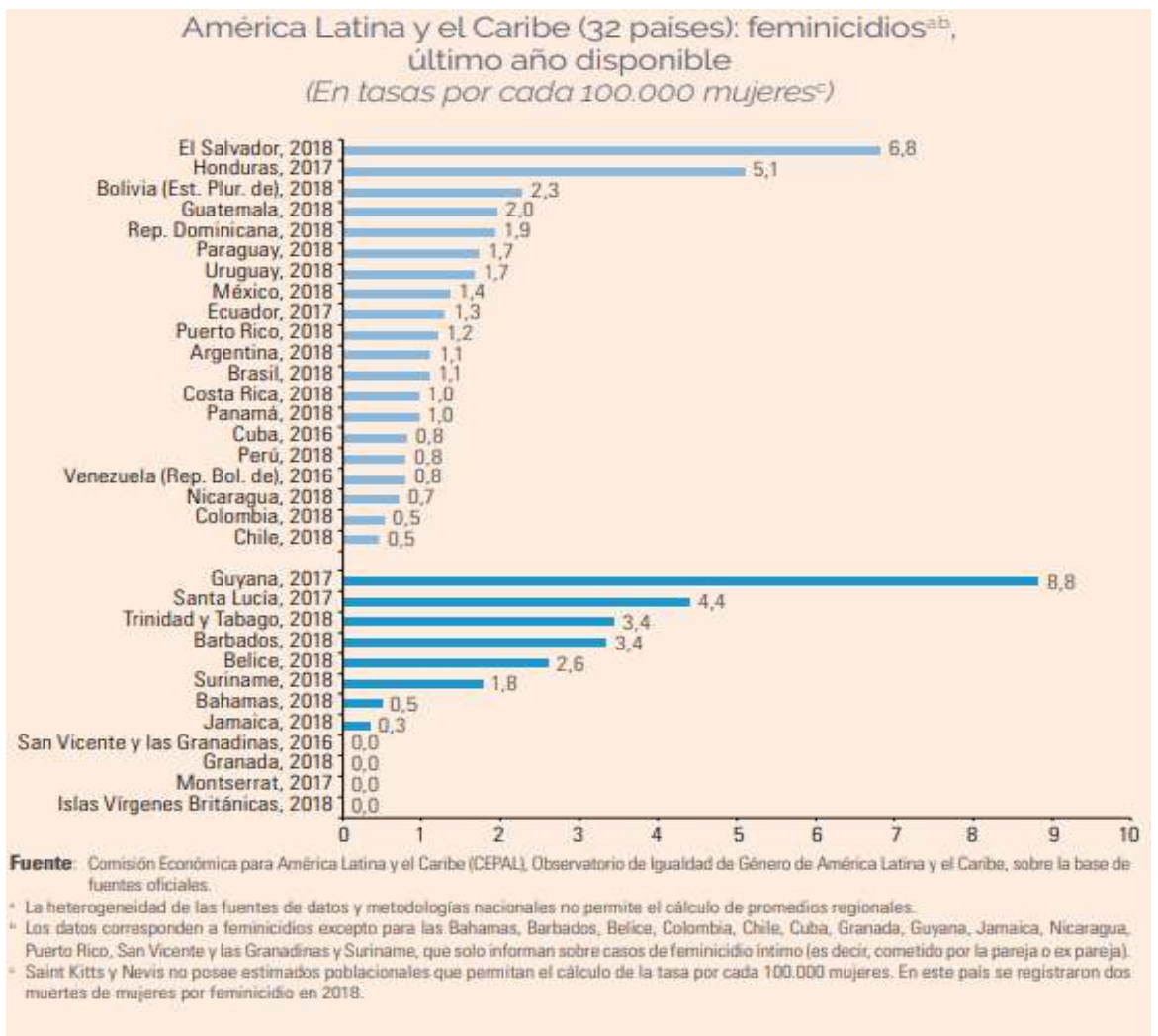

En la gráfica se aprecia que los países con mayor riesgo para las mujeres, contando los asesinatos de mujeres por sus parejas o ex parejas se da en América central con una tasa de $6.8 \%$ menor que en los países de América del Sur con el $8.8 \%$; donde el feminicidio de las mujeres es un problema social que tiende a demostrar que se trata de un tipo de crimen específico.

Saccomano (2017) apunta que la tasa de violencia contra las mujeres en América Latina es de $40,63 \%$ en comparación a otras regiones donde la tasa disminuye como en Europa Occidental que es del $19.3 \%$ y en la andina $29,51 \%$.

En cuanto a feminicidios se refiere, el continente americano tiene una tasa elevada del $40,5 \%$, ocupando el segundo lugar, detrás del Sudeste Asiático, con un $58,8 \%$.

En México, el Secretariado Ejecutivo del Sistema Nacional de Seguridad Pública, señaló que del periodo 2015 al 2020 la tendencia de feminicidio ha ido al alza. 
Tabla 2. Índice de feminicidio en México periodo 2015-2020.

\begin{tabular}{|c|c|c|c|c|c|}
\hline $\mathbf{2 0 1 5}$ & $\mathbf{2 0 1 6}$ & $\mathbf{2 0 1 7}$ & $\mathbf{2 0 1 8}$ & $\mathbf{2 0 1 9}$ & $\mathbf{2 0 2 0}$ \\
\hline 411 & 605 & 742 & 893 & 942 & 940 \\
\hline
\end{tabular}

Fuente: Elaboración propia

Cabe destacar que desde el 2015 hasta el 2019, el feminicidio ascendió, en el 2020 fueron de 940 las víctimas, disminuyendo, por tan solo dos personas menos que el año anterior. Ante dicho número se recalca la situación del virus Sar-Covid-19 que propició el resguardo de las personas en sus hogares, por otra parte, aumentó el número de delitos de violencia familiar.

En la tabla 3. Se desglosa datos del 2015 al 2020, sobre cómo va la tendencia nacional de la violencia familiar aumento tan solo en el año 2020.

\begin{tabular}{|c|c|c|c|c|c|}
\hline $\mathbf{2 0 1 5}$ & $\mathbf{2 0 1 6}$ & $\mathbf{2 0 1 7}$ & $\mathbf{2 0 1 8}$ & $\mathbf{2 0 1 9}$ & $\mathbf{2 0 2 0}$ \\
\hline 127,424 & 153,893 & 169,579 & 180,187 & 210,158 & 220,039 \\
\hline
\end{tabular}

Fuente: Elaboración propia

El delito de violencia familiar tuvo un incremento gradual de aproximadamente 9881 durante el año 2019 a 2020.

\section{Acercamiento a una percepción del feminicidio.}

Este acercamiento de percepción fue realizado con jóvenes estudiantes de una universidad pública del área de salud en el estado de Tabasco, México. El instrumento aplicado fue un cuestionario construido con base a 11 reactivos teniendo como población al género femenino y una muestra de cien mujeres mayores de 18 años. Los resultados de la percepción del feminicidio fueron los siguientes:

Gráfica 3. Conocimiento de que es el feminicidio

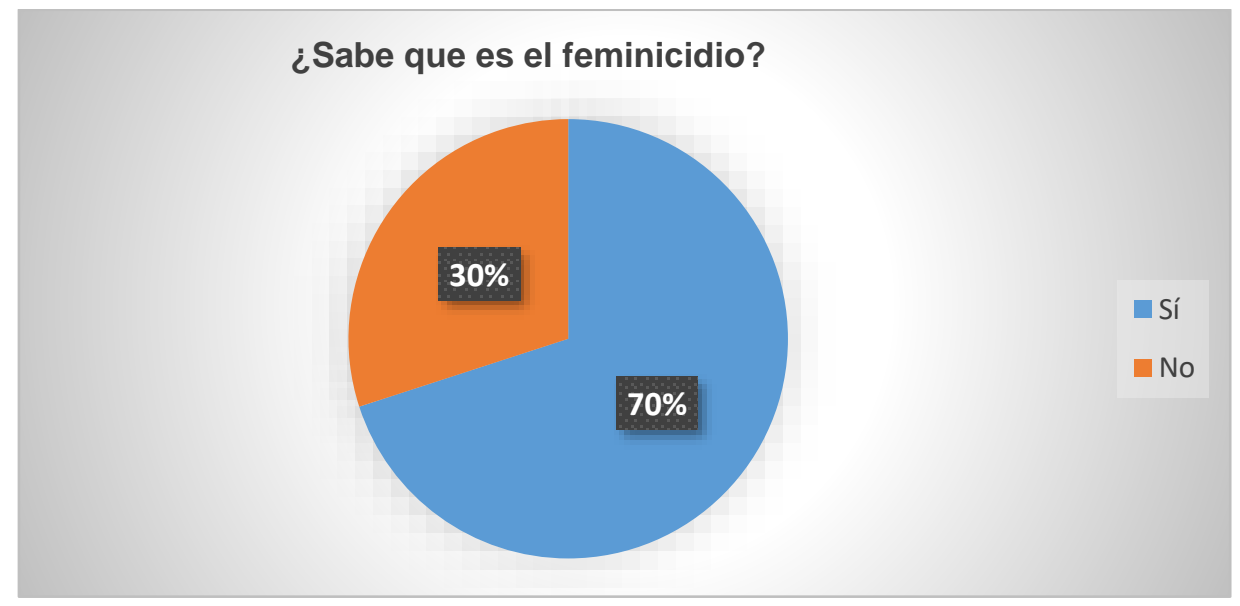


Aun cuando a la muestra seleccionada fue del género femenino un $30 \%$ desconoce todavía o tiene una idea vaga de lo que es feminicidio.

Gráfica 4. Nivel socioeconómico que considera se da el feminicidio

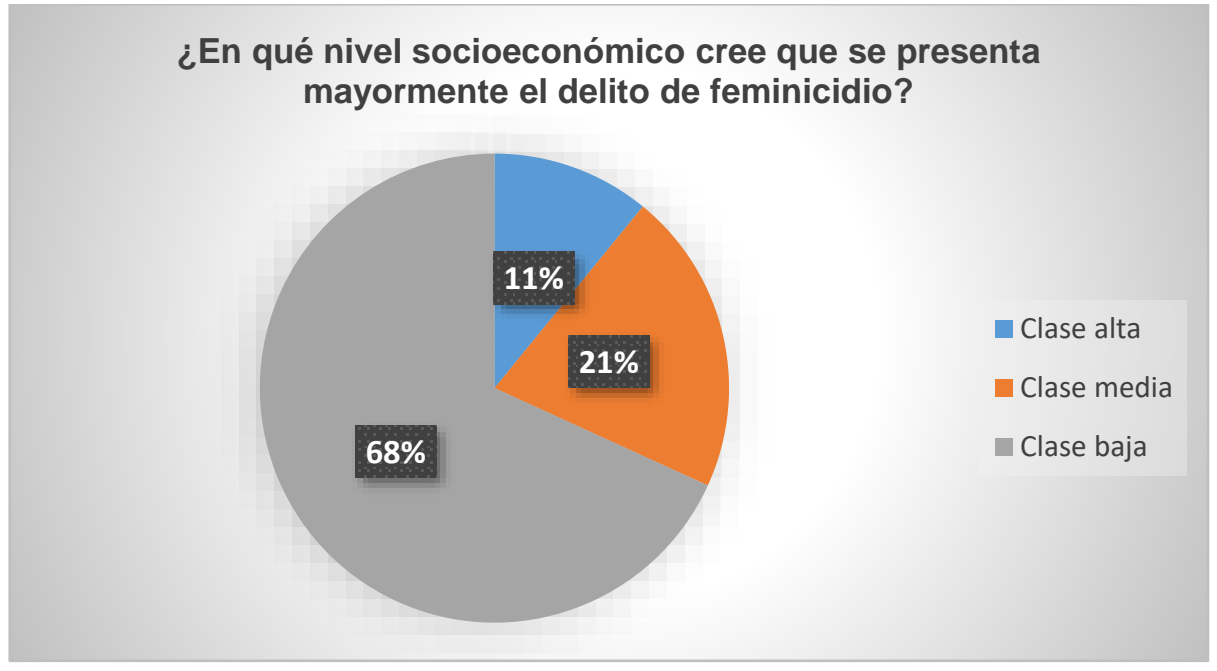

La gráfica 4 apunta en que las jóvenes estudiantes asocian el feminicidio con el factor socioeconómico en nivel bajo, como un factor en el que se plasma de forma recurrente el delito.

Gráfica 5. Conocimiento de personas que hayan realizado violencia a mujeres

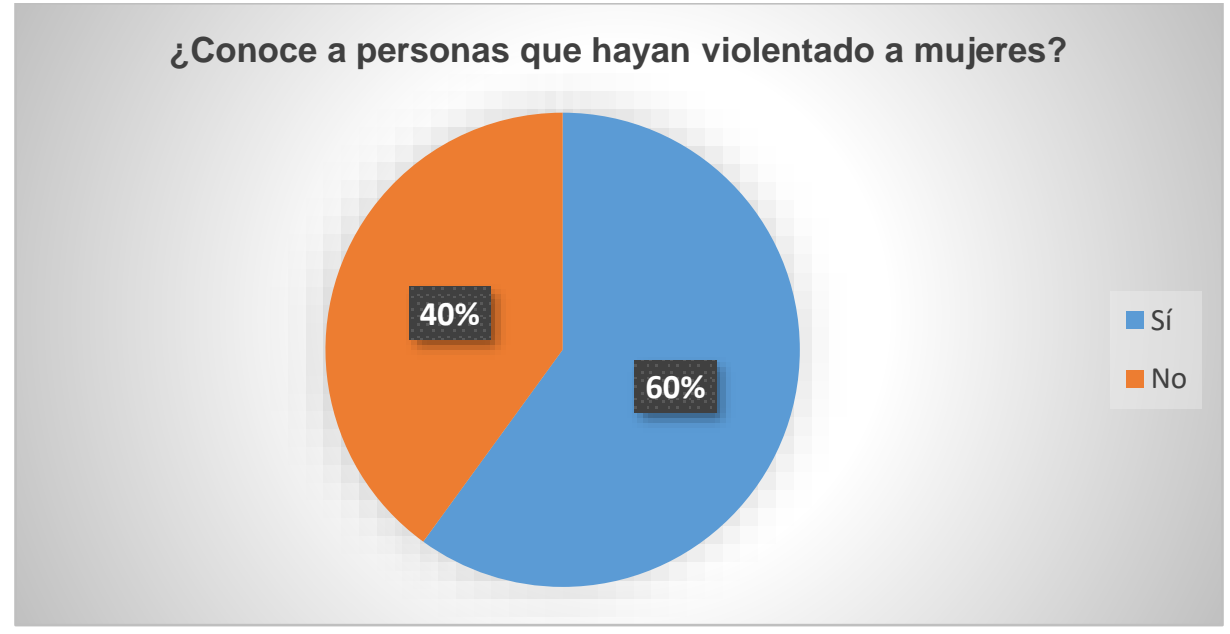

En esta gráfica es alarmante que se pueda llegar a visualizar como algo normal cualquier tipo de violencia a una mujer y peor en una edad joven. Como se señala el $60 \%$ de las mujeres dicen conocer a una persona que generó violencia sexual, verbal, física. 
Gráfica 6. Factores que considera influye en los agresores

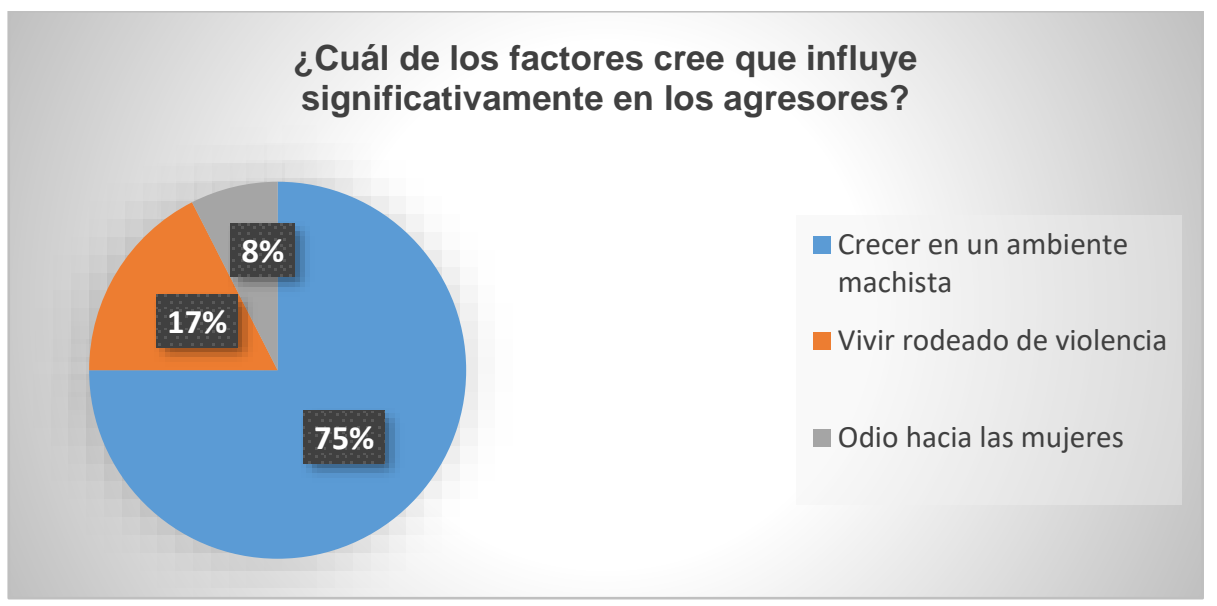

Las jóvenes estudiantes en el ámbito de su percepción el $75 \%$ señala que el crecer en un ambiente machista hace proliferar actos y actitudes de violencia de género.

Gráfica 7. Temor de salir sola a la calle.

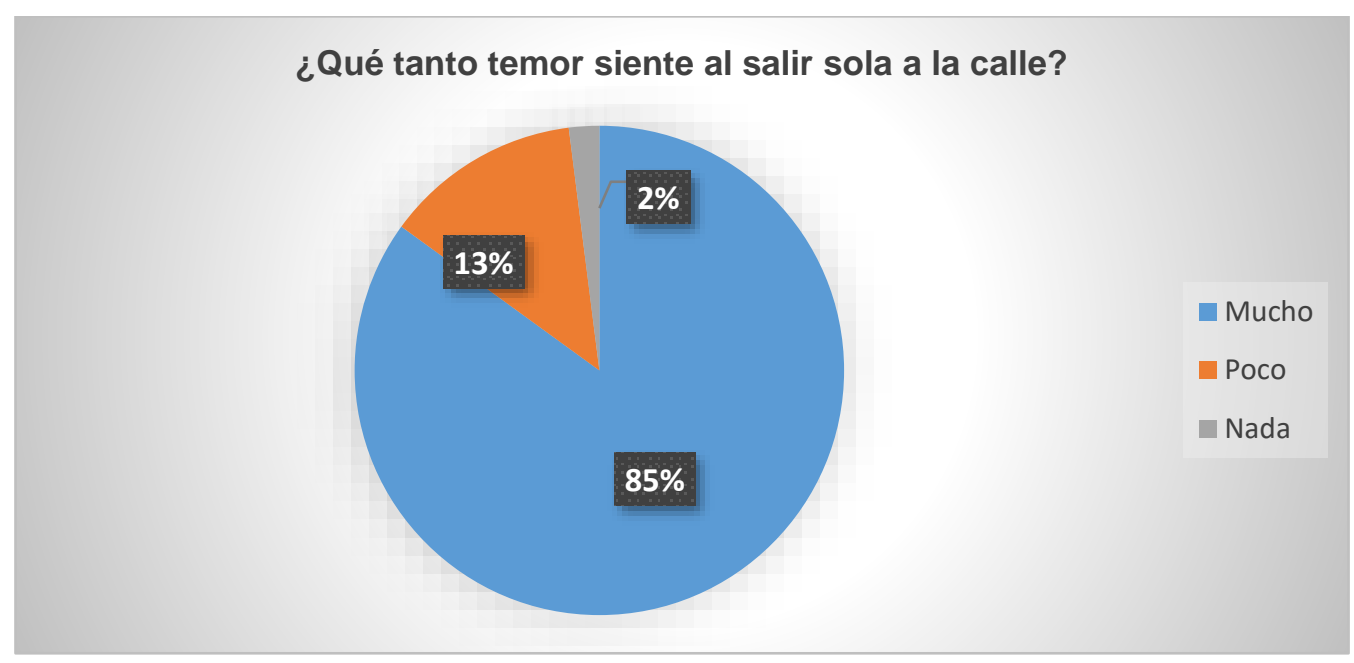

Está gráfica señala que un porcentaje del $2 \%$ de mujeres no tienen temor de salir solas, mientras que el $85 \%$ tiene un gran índice de temor de no sentirse seguras al estar en las calles.

Sin duda, la percepción de las mujeres jóvenes encuestadas apunta a considerar aspectos sociales, económicos, culturales en la generación, permanencia y aumento de actos de violencia de género de forma específica en 
las mujeres, de igual forma reconocer el trabajo que falta como sociedad ante este tipo de delito.

\section{Conclusiones}

El feminicidio más allá de una cuestión de género representa el poner en riesgo y en estado de vulnerabilidad a una persona. En este caso las mujeres han tenido un reconocimiento e incremento de participación en distintos escenarios y ámbitos a nivel global, nacional y local. Por lo que, los cambios estructurales de la sociedad consideran cambios de comportamientos y conciencia en los roles de participación de la mujer y el hombre.

En ese sentido, algunos cambios no han sido bien aceptados, la sociedad patriarcal ha jugado un papel muy importante detonando acciones de violencia en diversos aspectos en contra de la mujer a grado tal de generar un tipo de delito como lo es el feminicidio. Lamentablemente ninguna mujer está exenta y puesta en riesgo ante dicha situación, pero si pone en alerta a una sociedad que mediante acciones de política públicas en instancias respectivas puede prever mecanismos de acciones de conocimiento, concientización, prevención y mitigación de actos delictivos como el feminicidio.

\section{Referencia}

Albarrán, Jenny. (2015). Referentes conceptuales sobre femicidio/feminicidio. Su incorporación en la normativa jurídica venezolana. Revista Comunidad y Salud, 13(2), 75-80.

CEPAL. (2019). Indicadores. Feminicidio. Naciones Unidas: Observatorio de Igualdad de Género de América Latina y el Caribe.

Diario Oficial de la Federación. (1931). Código Penal Federal. Última reforma publicada DOF 19-02-2021.

CNDH. (2020). Diagnóstico de la Comisión Nacional de los Derechos Humanos como integrante de los grupos de trabajo que dan seguimiento a los procedimientos de Alerta de Violencia de Género contra las Mujeres (AVGM). México: CNDH.

CNDH. (2020). La CNDH exhorta a las autoridades de todos los niveles a difundir campañas información sobre el contexto real de la violencia en 
contra de las mujeres ante la pandemia por COVID-19. México: Dirección general de comunicación.

Deus, Alicia y González, Diana. (2018). Análisis de legislación sobre femicidio/feminicidio en américa latina y el caribe e insumos para una ley modelo. Panamá: ONU-Mujeres.

Gaceta del Semanario Judicial de la Federación. (2018). Feminicidio. En cumplimiento a las recomendaciones de la corte interamericana de derechos humanos, en la sentencia dictada en el caso González y otras (campo algodonero) vs. México, los datos de violencia previa y concomitante al asesinato de una mujer, son elementos que deben conducir a la calificación de los hechos en este delito. México: SCJN.

Hernández Sampieri, Roberto, Fernández Collado, Carlos \& Baptista Lucio, María del Pilar. (2014). Metodología de la investigación. México: Mc Graw Hill.

Incháustegui Romero Teresa. (2014). Sociología y política del feminicidio; algunas claves interpretativas a partir de caso mexicano. Revista Sociedade e Estado, 29(2), 373-400.

Jiménez Rodríguez, Nayibe Paola. (2011). Femicidio/Feminicidio: Una salida emergente de las mujeres frente a la violencia ejercida en contra de ellas. Revista Logos Ciencia \& Tecnología. 3(1), 127-148

Oficina de las Naciones Unidas contra la Droga y el Delito. (2019). Nuevo estudio de UNODC revela: El hogar, el lugar más peligroso para las mujeres. ONU.

Pineda G. Esther. (2019). Opinión: México lidera los feminicidios en América Latina. México: CC NEWS. Recuperado de: https://news.culturacolectiva.com/mexico/mexico-lidera-los-feminicidiosen-america-latina/

RAE. (2021). Feminismo. Asociación de Academia de la Lengua Española.

Saccomano, Celeste. (2017) El feminicidio en América Latina: ¿vacío legal o déficit del Estado de derecho? Revista CIDOB d'Afers Internacionals, $117(\mathrm{~s} / \mathrm{v}), 51-78$. 
Secretariado Ejecutivo del Sistema Nacional de Seguridad Pública. (2020). Información sobre violencia contra las mujeres. Incidencia delictiva y Ilamadas de emergencia 911. México: Centro Nacional de Información.

Cómo citar este articulo:

Martínez Prats, G., Isidro Arias, S., \& Silva Hernández, F. (2021). Apuntes del feminicidio y violencia de género. Revista De Investigación Académica Sin Frontera: División De Ciencias Económicas Y Sociales, (35), 13. https://doi.org/10.46589/rdiasf.vi35.371

https://revistainvestigacionacademicasinfrontera.unison.mx/index.php/RDIASF/article/view/371

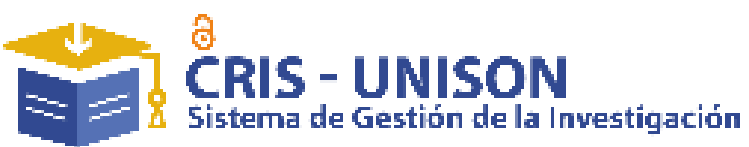

\section{Dia net}

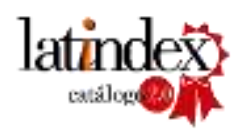

If lifactor
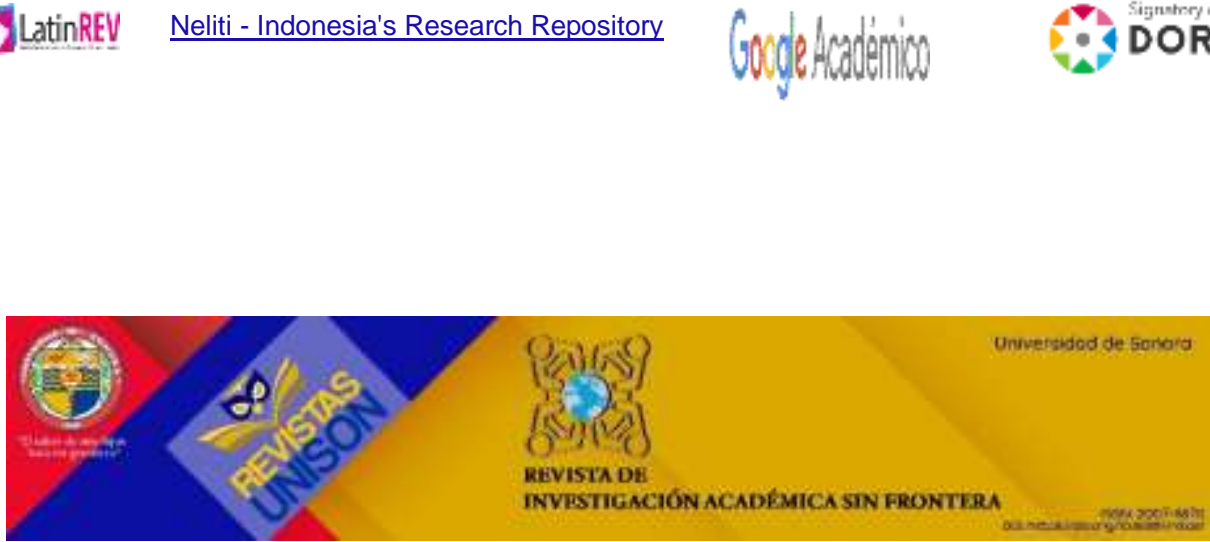